\title{
Characterization of 'Honeycrisp’ and ‘McIntosh’ Apple Juice Quality in Relation to Delayed Cooling Treatments
}

\author{
Jingfei Gao and H.P. Vasantha Rupasinghe*
}

Department of Environmental Sciences, Nova Scotia Agricultural College, PO Box 550, Truro, Nova Scotia, Canada B2N $5 E 3$

\begin{abstract}
In order to examine the influence of delayed cooling on juice quality, seven and three days of delayed cooling were applied to 'Honeycrisp' and 'McIntosh' apples, respectively. After the delayed cooling treatment, apples were stored in refrigerated air (RA) and in three different controlled atmospheres (CA) for six months. Titratable acidity (TA) decreased over the storage period due to the delayed cooling treatment for both 'Honeycrisp' and 'McIntosh' apples. Lower TA was detected in RA-stored apples compared to CA-stored fruit. In addition, the lowest TA of the juice samples was detected when 'McIntosh' apples were stored in RA with no delayed cooling treatment.
\end{abstract}

Key words: Apple, delayed cooling, storage, low-acid juice, postharvest.

\section{INTRODUCTION}

The shelf-life of apples is affected by a number of factors, including pre-harvest, harvesting and storage technologies [1]. Management of postharvest and storage conditions is necessary for reducing the loss of apple fruit quality. Ripening of harvested apples is characterized by a decrease in acidity, firmness, starch, chlorophyll as well as an increase in flavour and soluble solids [2]. The concentrations of organic acids generally decrease during fruit development to reach a low level during maturation and ripening [3]. Acidity in fruit declines during storage, but declining rates are different under different storage conditions, such as temperature, $\mathrm{CO}_{2}$ and $\mathrm{O}_{2}$ concentration as the metabolism and respiration rate are affected by these factors [4]. In comparison with refrigerated air (RA) storage, controlled atmosphere (CA) storage offers the advantage of preserving apple fruit quality for an extended period of time [4]. Apples kept in CA in which $\mathrm{O}_{2}$ levels are below $2.5 \%$ are generally firmer and have lower incidences of superficial scald and core flush [4]. A rapid decline of titratable acidity (TA) can occur during RA storage $\left(0^{\circ} \mathrm{C}\right)$ of 'McIntosh' apples [5]. The level of response to different CA conditions, such as low $\mathrm{O}_{2}$ atmospheres, varies with apple cultivars [4].

'Honeycrisp' is a new apple cultivar with a unique, crisp fruit texture that makes it highly desirable for fresh market. Although 'Honeycrisp' can develop bitter pit, watercore and skin puncture problems in storage, low storage temperatures $\left(3{ }^{\circ} \mathrm{C}\right.$ or lower) can facilitate the development of soft scald and low temperature breakdown [6]. Low temperature breakdown, watercore and soft scald are often observed in 'Honeycrisp' fruit which are harvested early and stored immediately at $3{ }^{\circ} \mathrm{C}$ in CA. Compared to that, fewer disorders develop in late-harvested fruit stored for a four-week period in

*Address correspondence to this author at the Tree Fruit Bio-product Research Program, Department of Environmental Sciences, Nova Scotia Agricultural College, PO Box 550, Truro, Nova Scotia, Canada B2N 5E3;

Tel: +1 902893 6623; Fax: +1 902893 1404; E-mail: vrupasinghe@nsac.ca
CA storage at $3{ }^{\circ} \mathrm{C}$ [7]. In general, apples are stored under cold or CA storage immediately after harvest. However, a delayed cooling treatment (stored at $20{ }^{\circ} \mathrm{C}$ for several days before storage in cold temperature condition) was recommended to significantly reduce the development of soft scald and low temperature breakdown of 'Honeycrisp' apples [8].

Apple juice consumption has decreased in Canada partly due to its high acidity [9]. As apples ripen, organic acids decrease and sugars accumulate. This process is accelerated at a higher temperature $\left(20^{\circ} \mathrm{C}\right)$ compared to refrigerated storage conditions. In this study, it was assumed that the degradation of organic acids could be accelerated and acidity decreased by applying a delayed cooling treatment to apples such as 'McIntosh'. Although delayed cooling is not recommended for 'McIntosh' fruit, a three-day delayed cooling treatment, was applied to 'McIntosh' prior to storage to investigate whether apple juice acidity could be reduced after storage.

The general objective of this study was, therefore, to examine the influence of delayed cooling treatments and different CA environments on the juice acidity of 'Honeycrisp' and 'McIntosh' apples.

\section{MATERIALS AND METHODS}

\subsection{Apples and Storage Environments}

'Honeycrisp' apples were harvested from Kentville, Annapolis Valley, NS, (late October, 2009) and 'McIntosh' apples were obtained from J.W. Mason \& Sons Limited, Windsor, NS, (harvested in late September, 2009). 'Honeycrisp' fruit were held at room temperature $\left(20 \pm 1{ }^{\circ} \mathrm{C}\right)$ for seven days (delayed cooling) immediately following harvest. One-half of the 'McIntosh' apples were kept at room temperature $\left(20 \pm 1^{\circ} \mathrm{C}\right)$ for three days, and were then stored at 3 ${ }^{\circ} \mathrm{C}$ in refrigerated air (RA) and several controlled atmosphere $\left(2 \% \mathrm{O}_{2}\right.$ and $2.5 \% \mathrm{CO}_{2} ; 0.7 \% \mathrm{O}_{2}$ and $2 \% \mathrm{CO}_{2}$ or $0.7 \% \mathrm{O}_{2}$ and $0 \% \mathrm{CO}_{2}$ ) storages at $3{ }^{\circ} \mathrm{C}$ for six months. The other half were not delayed cooled and were put into their storage envi- 
ronments after harvest. The 'Honeycrisp' fruit were stored in similar storage regimes after delayed cooling. The chlorophyll fluorescence-based HarvestWatch ${ }^{\mathrm{TM}}$ system (Bacharach Europe, Warwickshire, UK) was used to monitor the fruit response to the CA and RA environments and allows for the lowest possible $\mathrm{O}_{2}$ level [10]. The CA atmosphere was monitored and controlled by a David Bishop Instrument Oxystat ${ }^{\circledR} 2002$ system (Bacharach Europe, Warwickshire, UK). The apples (15 apples) were sampled at harvest time, after seven days delayed cooling and after six months storage and were pressed to juice using a commercial juice extractor (Breville, Elite 800 JEXL, Breveill, USA) in triplicate for analysis.

\subsection{Determination of Chemical Parameters of Juice Quality}

Total soluble solids, $\mathrm{pH}$ and TA were analyzed in triplicate juice samples. Total soluble solid (TSS; ${ }^{\circ}$ Brix units) was determined with a hand-held refractometer (Model 300016, Super Scientific Ltd., Scottsdale, AZ) at room temperature. The TA was measured using the semi-automated titrator (DMP 785, Metrohm Ltd., Herisau, Switzerland) at pH 8.2 using $0.1 \mathrm{~N} \mathrm{NaOH}$ as the titrant and was expressed as malic acid equivalents, the predominant acid in apple juice. The ${ }^{\circ}$ Brix: acid ratio was also calculated and compared. The $\mathrm{pH}$ value was determined by using a standardized $\mathrm{pH}$ meter (Model Accumet ${ }^{\circledR}$ 10, Denver Instruments Co., Arvada, Colorado, USA). Fruit firmness (N) was measured on the red and green sides of individual apples with the fruit quality tester (Geo-Met Instrument, New Minas, NS) with the time limit window set at $>0.1$ and $<1.0 \mathrm{~s}[11]$.

\subsection{Experimental Design and Statistics}

For statistical analysis, a completely randomized block design was used with four different storage environments and three sample periods as blocking factors and three sample replicates per treatment. Treatments were separated using the Tukey's multiple range means separation with statistically significant differences at $\mathrm{p} \leq 0.05$ (SAS Institute, Cary, NC, USA).

\section{RESULTS AND DISCUSSIONS}

\subsection{Effects of Delayed Cooling on Fruit and Juice Qual- ity of 'Honeycrisp' Apples}

Colour (\% Red) and firmness of 'Honeycrisp' apple was not affected by delayed cooling treatment and subsequent storage environments (Table 1). Apple firmness did not change after the delayed cooling treatment or after a sixmonth storage period. The seven day pre-storage delayed cooling regime was associated with reduced acidity of 'Honeycrisp' apple juice after the storage period (Table 2).

Apple mass slightly decreased after the 7-day delay cooling treatment plus RA and CA storage at $2 \% \mathrm{CO}_{2}$ (Table 1). $\mathrm{pH}$ and total soluble solids (TSS) increased in 'Honeycrisp' apple juice after six months storage except for $\mathrm{pH}$ of CAstored fruit held at $2 \% \mathrm{O}_{2}+2.5 \% \mathrm{CO}_{2}$ (Table 2). TA did not significantly reduce after six months cold storage, except TA of RA stored apples.

TA declined after delayed cooling since organic acids, such as malic acid, were respired as carbon sources and stored as sugars. The increases in $\mathrm{pH}$ and total soluble solids

Table 1. Influence of Delayed Cooling (DC) on Quality of ‘Honeycrisp’ Apples Following the Different Storage Environments

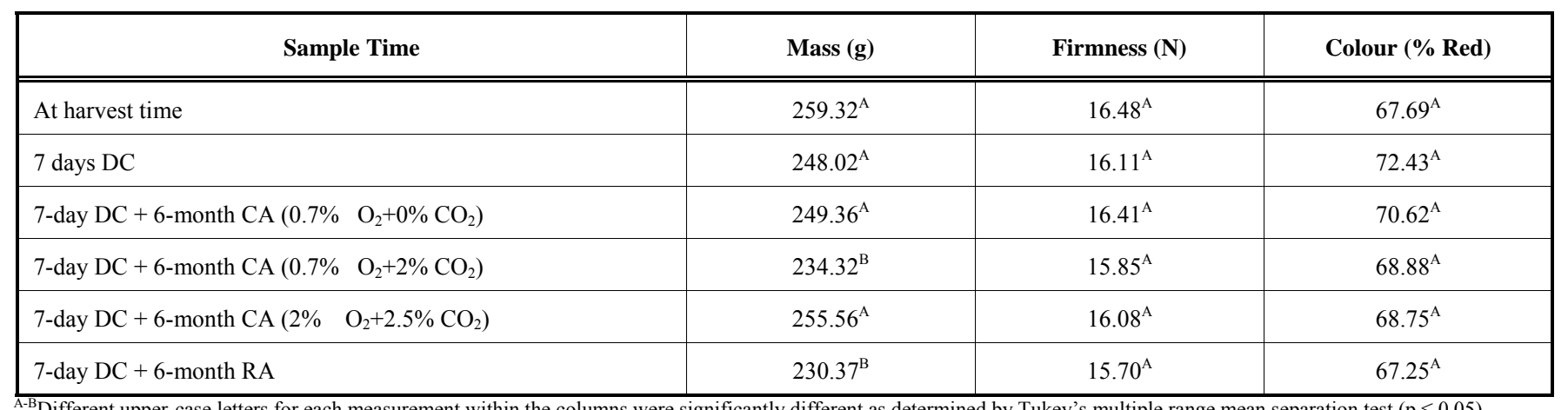

${ }^{A-B}$ Different upper-case letters for each measurement within the columns were significantly different as determined by Tukey's multiple range mean separation test ( $\left.\mathrm{p} \leq 0.05\right)$.

Table 2. Influence of Delayed Cooling (DC) on 'Honeycrisp’ Apple Juice Quality following the Different Storage Environments

\begin{tabular}{|c|c|c|c|c|}
\hline Sample Time & pH & TA (mg/100g Juice) & TSS & Yield (mL/g) \\
\hline 7-day DC +6 -month CA $\left(0.7 \% \mathrm{O}_{2}+0 \% \mathrm{CO}_{2}\right)$ & $3.32^{\mathrm{A}}$ & $603.0^{\mathrm{B}}$ & $12.5^{\mathrm{A}}$ & $0.50^{\mathrm{B}}$ \\
\hline 7-day DC + 6-month CA $\left(0.7 \% \mathrm{O}_{2}+2 \% \mathrm{CO}_{2}\right)$ & $3.35^{\mathrm{A}}$ & $592.9^{\mathrm{B}}$ & $12.1^{\mathrm{A}}$ & $0.56^{\mathrm{B}}$ \\
\hline 7-day DC + 6-month RA & $3.30^{\mathrm{A}}$ & $576.2^{\mathrm{B}}$ & $12.4^{\mathrm{A}}$ & $0.52^{\mathrm{B}}$ \\
\hline
\end{tabular}


were associated with organic acids degradation as well. Similarly, TA decline was observed over a delayed cooling treatment (seven days at $20^{\circ} \mathrm{C}$ ) and storage period by Watkins et al. [12]. 'McIntosh' TA decreased after one-day delayed cooling in the Watkins study [12]. Phenolic acids were reported to decline during cold storage [3]. However, it was reported that flavonoids presented in apples were stable during the storage [13]. The concentration of flavonoids and chlorogenic acid were not significantly different in 'Jonagold' and 'Elstar' apples stored under low oxygen compared to standard cold storage in air [13]. Decline of apple mass and juice yield are due to the loss of water and some volatile compounds. Water-loss $(1.18-1.28 \%)$ was observed in 'Honeycrisp' apples during seven days at $20{ }^{\circ} \mathrm{C}$ warming delayed cooling period [8].

Firmness is an important market-related apple quality attribute. The data indicated that firmness and apple colour of 'Honeycrisp' fruits were not influenced by delayed cooling at $20{ }^{\circ} \mathrm{C}$ before cold storage for six months (Table 1). The same results were observed by Watkins et al. [12]. In general, delays at warmer temperatures before cold storage of apple fruit are not recommended due to softening rates and the loss of their marketable quality [14]. Firmness can be affected by harvest time as firmness steadily decreased in late harvest 'Golden Reinders' apples [1]. 'Honeycrisp' is identified as a unique apple cultivar because of its slow softening characteristics, by which it maintains its firmness for long periods even under air storage [15]. Colour, such as redness, and other sensory quality characteristics of apples are influenced by phenolic substances [3]. Some important phenolics in 'Granny Smith' apple skin, such as epicatechin, quercetin glycosides and procyanidins decreased from day 100 to the end of storage at day 205 , both in air and controlled atmosphere (CA) storage $\left(1.0 \% \mathrm{O}_{2}+2.0 \% \mathrm{CO}_{2}\right)$, and further declines were found during one week of shelf-life at $20{ }^{\circ} \mathrm{C}[16]$.

A drop in soluble solids concentration (SSC, from $16.2 \%$ to $14.8 \%$ ) occurs throughout the ripening or shelf-life period [1]. This decline could be explained by fruit respiration during the storage period $\left(20^{\circ} \mathrm{C}, 48\right.$ days), since sugar and other fruit metabolites are depleted during respiration, contributing to a loss of fruit quality and carbohydrate reserves [1]. In the present study, TSS increased during cold storage in Honeycrisp fruit (Table 2). TSS, inversely associated with TA and firmness, ensures good apple quality and therefore the delayed cooling treatment and storage did not reduce the apple quality for consumer requirements.

\subsection{Effects of Delayed Cooling on Acidity of 'McIntosh' Apple Juice}

Juice $\mathrm{pH}$ increased after six-month storage in both delayed cooling and non-treated McIntosh apples. Also juice $\mathrm{pH}$ showed no difference in apples stored in different storage environments (Table 3). TA significantly decreased in both delayed cooled and non-delay cooled apples. Juice prepared from RA stored apples had lower TA compared to juice from apples stored in CA conditions (Table 3 ) and was less acidic. Among CA storage conditions, higher juice TA was detected at $0.7 \% \mathrm{O}_{2}+2 \% \mathrm{CO}_{2}$ in $\mathrm{CA}$ stored without DC-treated apples as well as $0.7 \% \mathrm{O}_{2}+2 \% \mathrm{CO}_{2}$ and $2 \% \mathrm{O}_{2}+2.5 \% \mathrm{CO}_{2} \mathrm{CA}$ stored with DC-treated apples. TSS was unchanged during the storage period. However, as TA declined, so did the TA/TSS ratio. The juice yield did not vary in six-month stored fruit.

TA of apples declined during ripening and continued to decrease during the storage period because organic acids are considered as a reserve source of energy of apples and would

Table 3. Influence of delayed cooling on 'McIntosh' apple juice quality following different storage environments

\begin{tabular}{|c|c|c|c|c|c|c|}
\hline Sample Time & pH & Malic Acid (g/L) & TA (mg/100g Juice) & TSS & TA/TSS & Yield (mL/g) \\
\hline At harvest & $3.04^{\mathrm{B}}$ & $7903^{\mathrm{A}}$ & $961.5^{\mathrm{A}}$ & 9.8 & $98.1^{\mathrm{A}}$ & $0.66^{\mathrm{A}}$ \\
\hline $\begin{array}{l}\text { No DC }+ \\
\text { 6-month CA }\left(0.7 \% \quad \mathrm{O}_{2}+0 \% \mathrm{CO}_{2}\right)\end{array}$ & $3.25^{\mathrm{A}^{*}}$ & $4187^{\mathrm{B}^{*}}$ & $529.3^{\mathrm{D}^{*}}$ & 11.3 & $46.8^{\mathrm{C}^{*}}$ & $0.56^{\mathrm{B}^{*}}$ \\
\hline 6-month CA $\left(2 \% \mathrm{O}_{2}+2.5 \% \mathrm{CO}_{2}\right)$ & $3.26^{\mathrm{A}^{*}}$ & $4213^{\mathrm{B}^{*}}$ & $529.3^{\mathrm{D}^{*}}$ & 11.6 & $45.6^{\mathrm{C}^{*}}$ & $0.53^{\mathrm{B}^{*}}$ \\
\hline 6-month RA & $3.30^{\mathrm{A}^{*}}$ & $3622^{\mathrm{B}^{*}}$ & $458.7^{\mathrm{E}^{*}}$ & 11.2 & $37.2^{\mathrm{D}^{*}}$ & $0.55^{\mathrm{B}^{*}}$ \\
\hline $\begin{array}{l}\text { 3-day DC + } \\
\text { 6-month CA }\left(0.7 \% \quad \mathrm{O}_{2}+0 \% \mathrm{CO}_{2}\right)\end{array}$ & $3.28^{\mathrm{A}^{*}}$ & $4116^{\mathrm{B}^{*}}$ & $525.9^{\mathrm{D}^{*}}$ & 11.3 & $46.5^{\mathrm{C}^{*}}$ & $0.55^{\mathrm{B}^{*}}$ \\
\hline 6-month RA & $3.33^{\mathrm{A}^{*}}$ & $3897^{\mathrm{B}^{*}}$ & $432.4^{\mathrm{E}^{*}}$ & 11.4 & $41.4^{\mathrm{C}^{*}}$ & $0.53^{\mathrm{B}^{*}}$ \\
\hline
\end{tabular}

A-E Different upper-case letters for each measurement within the columns were significantly different as determined by the Tukey's multiple range mean separation test with statistically significant differences at $\mathrm{p} \leq 0.05$.

*indicates significant difference between stored apples and just-harvested apples at significant levels of $\mathrm{p} \leq 0.05$. 
be expected to decline during the metabolic activity that occurs during ripening. Accelerated ethylene production was found in later-harvest of (three, seven and ten days after commercial harvest time) 'McIntosh' apples [17]. Ethylene induces higher respiration rates and therefore stimulates the conversion of organic acids to sugars. Heat treatment $\left(38{ }^{\circ} \mathrm{C}\right.$ for four days) of 'Lodi' apples was reported to cause higher respiration and lower TA than control apples [18]. However, our data indicated that juice prepared from RA stored apples (with or without three days delayed cooling) has lower acidity. Prolong delayed cooling may cause internal browning disorder in apples [6] and therefore, further research is recommended for application of delayed cooling treatment for 'McIntosh' apple storage for the purpose low-acid apple juice manufacturing.

\section{CONCLUSION}

In conclusion, a pre-storage delayed cooling treatment decreased acidity in 'Honeycrisp' and 'McIntosh' apple juice. Lower TA was detected in RA-stored 'McIntosh' apples when compared to fruit stored in three other CA regimes. 'Honeycrisp' apple qualities, such as firmness and colour (\% of red) did not change during the seven days of delayed cooling and the six months storage period. Therefore, seven days delayed cooling at $20{ }^{\circ} \mathrm{C}$ is recommended for 'Honeycrisp' apples for the purpose of obtaining lowacid apple juice. Three days delayed cooling is not recommended for 'McIntosh' apples, since apple juice from RA storage was not significantly different in TA compared with delayed cooled fruit. Late harvesting or applying delayed cooling at higher temperatures or for a longer period of time might be some alternative methods to reduce the acidity of 'McIntosh' apple juice.

\section{ACKNOWLEDGEMENT}

The financial support of this project was provided by $\mathrm{J}$. W. Mason and Sons Limited, Windsor, NS, Canada and the Atlantic Innovation Fund (AIF) of Atlantic Canada Opportunity Agency (ACOA). Authors would like to greatly appreciate the advice and support given by Dr. John DeLong of the Atlantic Food and Horticulture Research Centre, Agriculture and Agri-Food Canada, Kentville, Nova Scotia, Canada to complete this study.

\section{CONFLICT OF INTEREST}

The authors confirm that this article content has no conflicts of interest.

\section{ACKNOWLEDGEMENTS}

None Declared.

\section{REFERENCES}

[1] Altisent R, Echeverria G, Lara I, Lopez ML, Graell J. Shelf-life of 'Golden Reinders' apples after ultra low oxygen storage: effect on aroma volatile compounds, standard quality parameters, sensory attributes and acceptability. Food Sci Technol Int 2009; 15: 481-93.

[2] Dever MC, Cliff M, Lau OL. Maturity and ripening effects on chemical and sensory properties of apple juice. J Sci Food Agr 1992: 60: 355-60.

[3] Awad MA, de Jager A. Influences of air and controlled atmosphere storage on the concentration of potentially healthful phenolics in apples and other fruits. Postharvest Biol Tec 2003: 27: 53-8.

[4] Levesque PG, DeEll JR, Murr DP. Sequential controlled atmosphere storage for 'McIntosh' apples. HortScience 2006: 41: 1322-1324.

[5] Dever MC, Cliff M, Veto L. Effect of apple storage on the quality of non-oxidative juice. Can. J. Food Sci. Technol. 1991; 24: 252-8.

[6] DeLong JM, Prange RK, Leyte JC, Harrison PA. A new technology that determines low- $\mathrm{O}_{2}$ thresholds in controlled-atmosphere-stored apples. Horttechnology 2004b; 14: 262-6.

[7] Prange R, DeLong J, Leyte JC, Harrison PA. Storage of 'Honeycrisp' apples. Nova Scotia fruit growers. Annu Rep 2002; 138: 25-7.

[8] DeLong JM, Prange RK, Harrion PA. The influence of pre-storage delayed cooling on quality and disorder incidence in 'Honeycrisp' apple fruit. Postharvest Biol Tec 2004a: 33: 175-180.

[9] McIntosh RIW, Rupasinghe HPV, Embree C, Erith D. Apple-based bio-product: market and industry development analysis - Phase 1 Overview of existing markets for traditional apple products. New York: NSFGA 2006; 38.

[10] Prange RK, DeLong JM, Wright AH. Chlorophyll fluorescence - successful transfer of interesting science to practical applications in postharvest horticulture. Chron Horticult 2010; 50: 13-6.

[11] DeLong JM, Prange RK, Harrison PA, McRae KB. Comparison of a new apple firmness penetrometer with three standard instruments. Postharvest Biol Tec 2000; 19: 201-9.

[12] Watkins CB, Erkan M, Noc JF, Iungerman KA, Beaudry RM, Moran RE. Harvest date effects on maturity, quality, and storage disorders of 'Honeycrisp' apples. HortScience 2005; 40: 164-9.

[13] Awad MA, de Jager A. Flavonoid and chlorogenic acid levels in skin of Jonagold and Elstar apples during and after regular and ultra low oxygen storage. Postharvest Biol Tec 2000; 20: 15-24.

[14] Johnston JW, Hewett EW, Hertog ML, Harker FR. Temperature and ethylene affect indution of rapid softening in 'Granny Smith' and 'Pacific RoseTM' apple cultivars. Postharvest Biol Technol 2002; 25: 25764.

[15] Tong C, Krueger D, Vickers Z, et al. Comparison of softening-related changes during storage of 'Honeycrisp' apple, its parents and 'delicious'. J Am Soc Hortic Sci 1999; 124: 407-15.

[16] Piretti MV, Gallerani G, Pratella GC. Polyphenol fate and superficial scald in apple. Postharvest Biol Tec 1994; 4: 213-24.

[17] DeEll JR, Ayres JT, Murr DP. 1-methylcyclopropene concentration and timing of postharvest application alters the ripening of 'McIntosh' apples during storage. Horttechnology 2008;18: 624-30.

[18] Escalada VS, Archbold DD. Preharvest Aminoethoxyvinylglycine plus postharvest heat treatments influence apple fruit ripening after cold storage. HortScience 2009; 44: 1637-40. 